\title{
Targeted Synthesis and Environmental Applications of Oxide Nanomaterials
}

\author{
Ying Zhou and Greta R. Patzke*
}

\begin{abstract}
Oxide nanomaterials are indispensable building blocks for a future nanotechnology, because they offer an infinite variety of structural motifs that lead to their widespread technical application. Therefore, flexible and tunable preparative strategies are required to convert this large family of materials onto the nanoscale. Although hydrothermal syntheses have proven especially suitable for this purpose, their reaction pathways and mechanisms often remain unknown so that they can be difficult to control. In the following, we summarize our comprehensive approach towards nanostructured functional oxides that is based on synthetic parameter optimizations, mechanistic in situ investigations and the characterization of environmentally relevant properties, e.g. in photocatalysis or sensor technology. The connection between preparative morphology control and the resulting materials properties is demonstrated for selected tungstate systems and bismuth-containing oxides. Furthermore, different methods for the in situ monitoring of hydrothermal processes are discussed.
\end{abstract}

Keywords: Hydrothermal synthesis · in situ EXAFS/EDXRD · Nanomaterials · Oxides · Photocatalysis

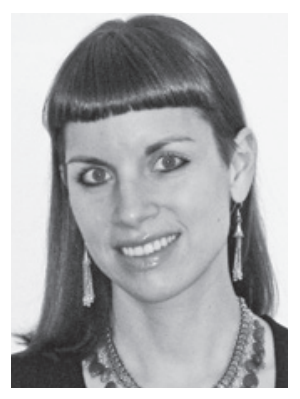

Since summer 2007, Greta R. Patzke is SNSF Professor (tenure track) at the Institute of Inorganic Chemistry at the University of Zurich. She was born 1974 in Bremen (Germany). From 1993 to 1997, she studied chemistry at the University of Hannover (Germany). Her diploma thesis covered solid state and computational chemistry.

In 1999, she received her doctoral degree summa cum laude from the University of Hannover. Her work was supported by the Studienstiftung des Deutschen Volkes, and she worked with Prof. Michael Binnewies on the synthesis, characterization and properties of mixed oxides with special emphasis on crystal growth methods from the gas phase.
She then moved to ETH Zürich and joined the group of Prof. Reinhard Nesper to work on her habilitation. During these years, she developed a wide range of research interests including structural inorganic chemistry, nanomaterials synthesis and the systematic application and investigation of hydrothermal techniques. She received the Venia Legendi for inorganic chemistry from ETH Zürich in October 2006. Her present research activities are focused on the targeted synthesis of functional inorganic materials, such as oxide nanomaterials for photocatalytic and sensor applications or bio-active polyoxometalates and hybrid materials thereof.

\section{Introduction}

With the beginning of the 21 st century, modern societies are facing a paradigm shift in their technological developments: it becomes increasingly clear that our present standards of living can only be maintained when the urgent issues of sustainable energy sources ${ }^{[1]}$ and constant access to clean water resources ${ }^{[2]}$ can be resolved. This calls for the development of new visible-light-driven catalysts in order to use a considerable fraction of the solar light for artificial photosynthesis ${ }^{[3]}$ as the key to hydrogen-based technology and to largescale wastewater treatment. Furthermore, the constant monitoring of environmental conditions on all levels from daily life to industrial productions is another important step to ensure a constant quality of life. ${ }^{4]}$ Here, materials chemistry can make an important contribution through the construction of new miniaturized sensor types that can be applied almost everywhere with minimum energy supply.[5] Nanotechnology will play a major role in all these areas as well as the setup of 'green chemistry' processes $^{[6]}$ for the large-scale production of the required new materials. A considerable fraction of them will be oxides, because this substance class offers an almost inexhaustible pool of structural types with according materials properties that can be tailored to meet current technological requirements. [7]

Our research activities are thus focused on the targeted synthesis of nanostructured oxide materials via convenient hydrothermal syntheses ${ }^{[8]}$ that offer manifold advantages: they can be run as 'green' one-step and waste-free reactions without organic solvents involved. In addition, hydrothermal reactions offer a wide range of parameter tuning options so that they are exceptionally suitable for transferring the manifold oxide types of technological interest onto the nanoscale. ${ }^{[9]}$ However, this remains a particular challenge for ternary oxides due to the three-fold task of phase, composition and morphology control that has to be mastered for their synthesis. Given that most of the oxide formation mechanisms under hydrothermal conditions are still difficult to predict in the absence of a generally applicable theoretical concept, we shed light into the 'black box' nature of the hydrothermal autoclave with in situ investigations monitoring the growth of oxide nanoparticles therein. These insights are of fundamental importance to optimize the large-scale processing of nanomaterials. Concerning the functionality of oxides, we focus on the synthesis of visible-light-driven oxide photocatalysts 
in order to amplify the use of the solar light spectrum, because $\mathrm{TiO}_{2}$ as the leading photocatalyst material in the field ${ }^{[10]}$ is restricted to the absorption of UV light representing only $4 \%$ of the light impinging on the earth's surface. In parallel, we tune the properties of oxide nanomaterials for water splitting, because the production of hydrogen through artificial photosynthesis with cheap, recyclable and non-toxic catalysts is our long-term goal.

Apart from our investigations on oxide nanoparticles, we also pursue the synthesis of new polyoxometalates (POMs): this ever-increasing class of oxoclusters attracts widespread research interest due to its fascinating range of molecular architectures and their equally wide application spectrum. ${ }^{[11]}$ Here, our efforts are directed on the biomedicinal properties of POMs, especially large lanthanoid-containing polyoxotungstates, ${ }^{[12]}$ and we combine them with biopolymers to enhance their antiviral, antitumor and antibacterial properties. [13]

In the following, we illustrate our comprehensive approach towards new oxide materials that starts out with creating new and facile syntheses, followed by their mechanistic understanding and it is rounded off with the investigation of their applications.

\section{Materials Synthesis: Hydrothermal Tuning of Oxide Nanomaterials with Inorganic Additives}

We aim for the environmentally friendly and scalable production of oxide nanomaterials along the following lines: the precursor materials should be air-stable and readily available and lead to the desired product in a minimum of reaction steps at rather low production temperatures. ${ }^{[14]}$ As mentioned above, matching these requirements with the difficulties of phase- and morphology-selective oxide synthesis is challenging so that we employ inorganic salts as auxiliaries or additives in order to direct the course of a hydrothermal reaction. Inorganic ionic additives are usually low-cost substances that can be easily removed after the reaction has been finished and they can play multiple roles, such as acting as mineralizers, changing the seed growth and reaction kinetics and modifying the reaction pathways through the selective interaction with specific crystal planes. ${ }^{[15]}$ Moreover, they can also exert a stabilizing effect via the incorporation into an otherwise unaltered open structural motif. ${ }^{[16]}$ Oxides with such versatile structures are, for example, found among the $\mathrm{W}$-, Mo- and V-containing transition metal oxides that also excel through their high application potential, e.g. in catalysis, sensor and battery technology. ${ }^{[17]}$ Over the past years, we have thus investigated their hydrothermal nanochemistry in combination with bismuth that opens up another large family of $\mathrm{Bi} /(\mathrm{W}, \mathrm{Mo}) / \mathrm{V}$-oxides with hitherto unexplored potential (also known as the BiMoVOx family). ${ }^{[18]}$ Among the W/Mo-oxides, their hexagonal representatives keep attracting research attention due to their channel-containing structure (Fig. 1 , middle) that gives rise to manifold exchange and incorporation processes. ${ }^{[19]}$

We have thus established a straightforward one-step hydrothermal approach towards nanoscale hexagonal W/Mo-oxides: the reaction of ammonium metatungstate and $\mathrm{MoO}_{3} \cdot 2 \mathrm{H}_{2} \mathrm{O}$ for $2 \mathrm{~d}$ at $180{ }^{\circ} \mathrm{C}$ affords phase-pure mixed W/Mo-materials. [20] This synthetic route can subsequently be tuned by using alkali chlorides as additives in the above-mentioned hydrothermal procedure. ${ }^{[16,21]}$ They exert a dual function: on the one hand, they stabilize the wide interior of the hexagonal channel system through intercalation and on the other hand, the morphology of the products can be steered with the alkali cation. The use of $\mathrm{LiCl}$ and $\mathrm{NaCl}$ gives rise to nanorod formation, whereas very small nanorods organize into cylinders that furthermore form spherical aggregates in the presence of $\mathrm{KCl}, \mathrm{RbCl}$ and $\mathrm{CsCl}$ (Fig. 1). ${ }^{[21]}$ Further parameter investigations of the hydrothermal system showed that the formation of the resulting hierarchical W/Mo-oxide architectures depends on the presence of the larger alkali cations $\mathrm{K}^{+}, \mathrm{Rb}^{+}$and $\mathrm{Cs}^{+}$. The question how this morphological variety can arise from a single hydrothermal protocol inspired us to investigate the reaction pathway with in situ methods.

\section{Understanding Materials: in situ Investigation of Oxide Nanomaterials Formation}

The main in situ methodologies that we apply for the monitoring of hydrothermal reactions are in situ XAS (X-ray absorption) and EDXRD (energy-dispersive Xray diffraction) methods. In situ EXAFS (extended X-ray absorption fine structure) and XANES (X-ray absorption near edge structure) techniques in particular are conducted in a specially constructed hydrothermal cell that permits the simultaneous monitoring of the solid and the liquid phase of a given hydrothermal reaction. ${ }^{[22]}$ This provides information regarding the occurrence of intermediates and the onset temperature of the reaction as a crucial economic factor. We have illustrated the benefits of this strategy in our study on the hydrothermal growth of $\mathrm{MoO}_{3}$ fibers: in situ EXAFS investigations of the liquid phase demonstrated that the formation of $\mathrm{MoO}_{3}$ nanorods already sets in around $100{ }^{\circ} \mathrm{C}$, whereas the stan-

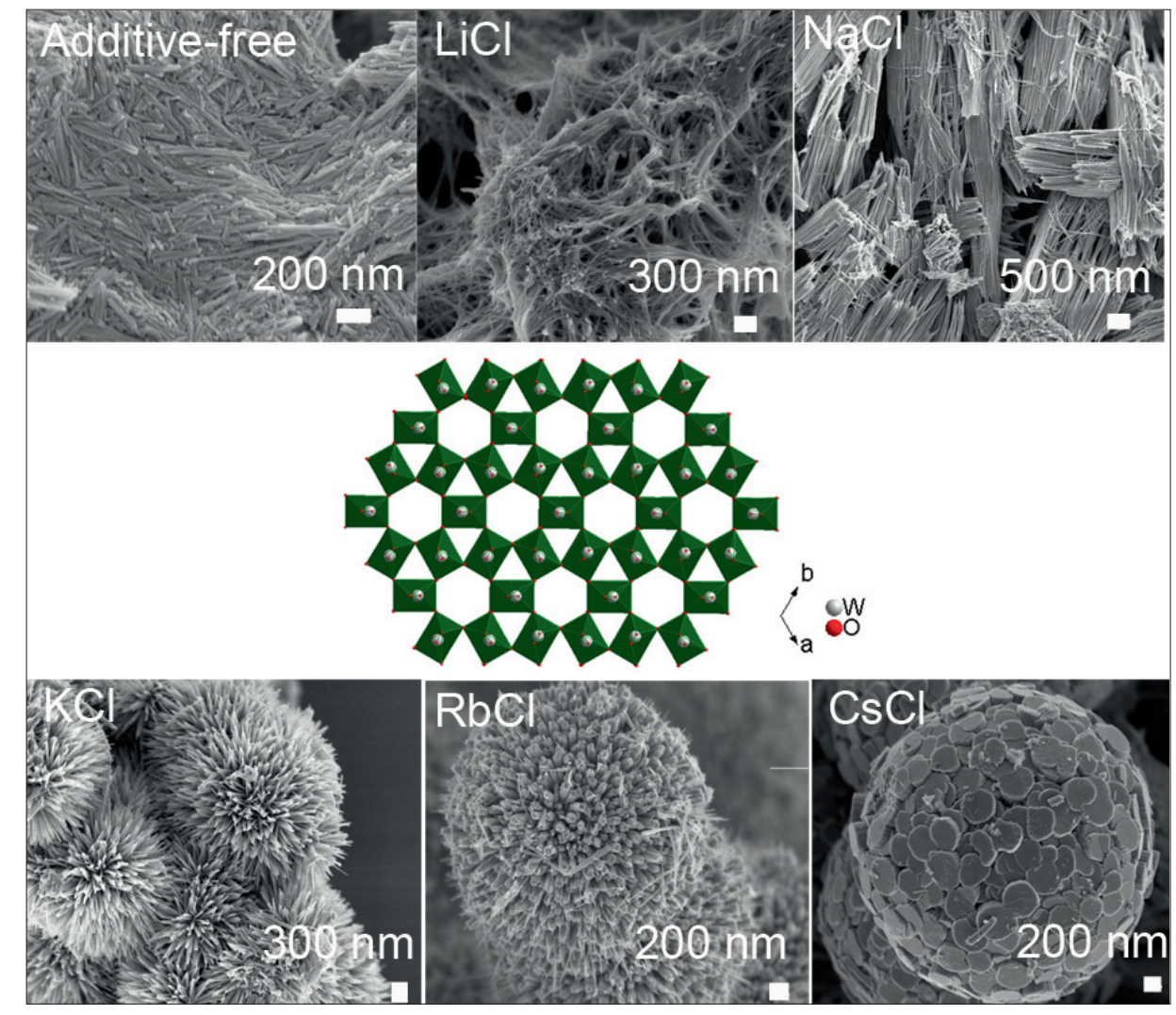

Fig. 1. Influence of alkali chloride additives on the morphology of hydrothermally synthesized hexagonal W/Mo-oxides exhibiting the characteristic channel structure motif (middle). 
dard laboratory protocol had been set up for $180{ }^{\circ} \mathrm{C} .{ }^{[23]}$ In situ EDXRD is a powerful complementary method that reveals the induction periods and reaction times of a given hydrothermal process through the evaluation of time-dependent $\mathrm{X}$-ray diffraction patterns. ${ }^{[24]}$ A more detailed comparison with physico-chemical models furthermore permits the assignment of hydrothermal formation mechanisms. Firstly, the induction time $t_{\text {ind }}$ is subtracted from $\mathrm{t}$, and $\ln [-\ln (1-\alpha)]$ versus $\ln (t)$ is plotted in the so-called Sharp-Hancock (SH) plot ( $\alpha=$ degree of reaction). ${ }^{[25]}$ A mechanistic change in the course of the reaction is indicated by change in the slope of the SH plot. Next, the experimental data are directly compared to different mechanistic models by plotting $t / t_{0.5}$ vs. $\alpha .{ }^{[26]}$ We have applied this strategy on the alkali chloride-assisted growth of hexagonal tungsten oxides. ${ }^{[16]}$ Here, the particle morphology and degree of organization of the obtained alkali tungstate nanorods varies with the alkali cation albeit not as pronounced as in the case of the mixed hexagonal W/Mo-oxides, e.g. their tungsten-based analogues do not display the organization into hierarchical spheres. In situ EDXRD measurements indicated that all nanostructured hexagonal tungstates are formed according to a nucleation controlled mechanism regardless of the alkali additive cation involved: the $\mathrm{SH}$ plots follow a straight line and the subsequent plot of $t / t_{0.5}$ vs. $\alpha$ agrees well with the model curve for nucleation control. In the case of hexagonal tungstates, the alkali cations only influence the reaction kinetics and the morphology, but not the formation mechanism of the nanostructured oxides. ${ }^{[16]}$

In situ EDXRD investigations on the hexagonal W/Mo-tungstates, however, revealed a different mechanistic scenario. The formation of nanorods in the presence of $\mathrm{Li}^{+}$and $\mathrm{Na}^{+}$follows complicated mechanistic sequences as indicated by the different subsequent slopes of the $\mathrm{SH}$ plots, whereas the spherical architectures obtained with $\mathrm{K}^{+} / \mathrm{Rb}^{+} / \mathrm{Cs}^{+}$-ions as additives all emerge from the same diffusion controlled mechanism so that their SH plots can be fitted with a straight line (Fig. 2). ${ }^{[27]}$

Interestingly, the origin of the more complex spherical morphologies can be mechanistically assigned in a straightforward manner to an isotropic diffusion model, whereas the formation of the nanorods follows a more complex mechanistic sequence. Therefore, we could establish a connection between the morphology of the nanostructured ternary transition metal oxides and their formation mechanism as an important step towards the hydrothermal morphology control of ternary oxides: such detailed studies are still rather rare but indispensable for mastering the hydrothermal process on a general scale. ${ }^{[27]}$

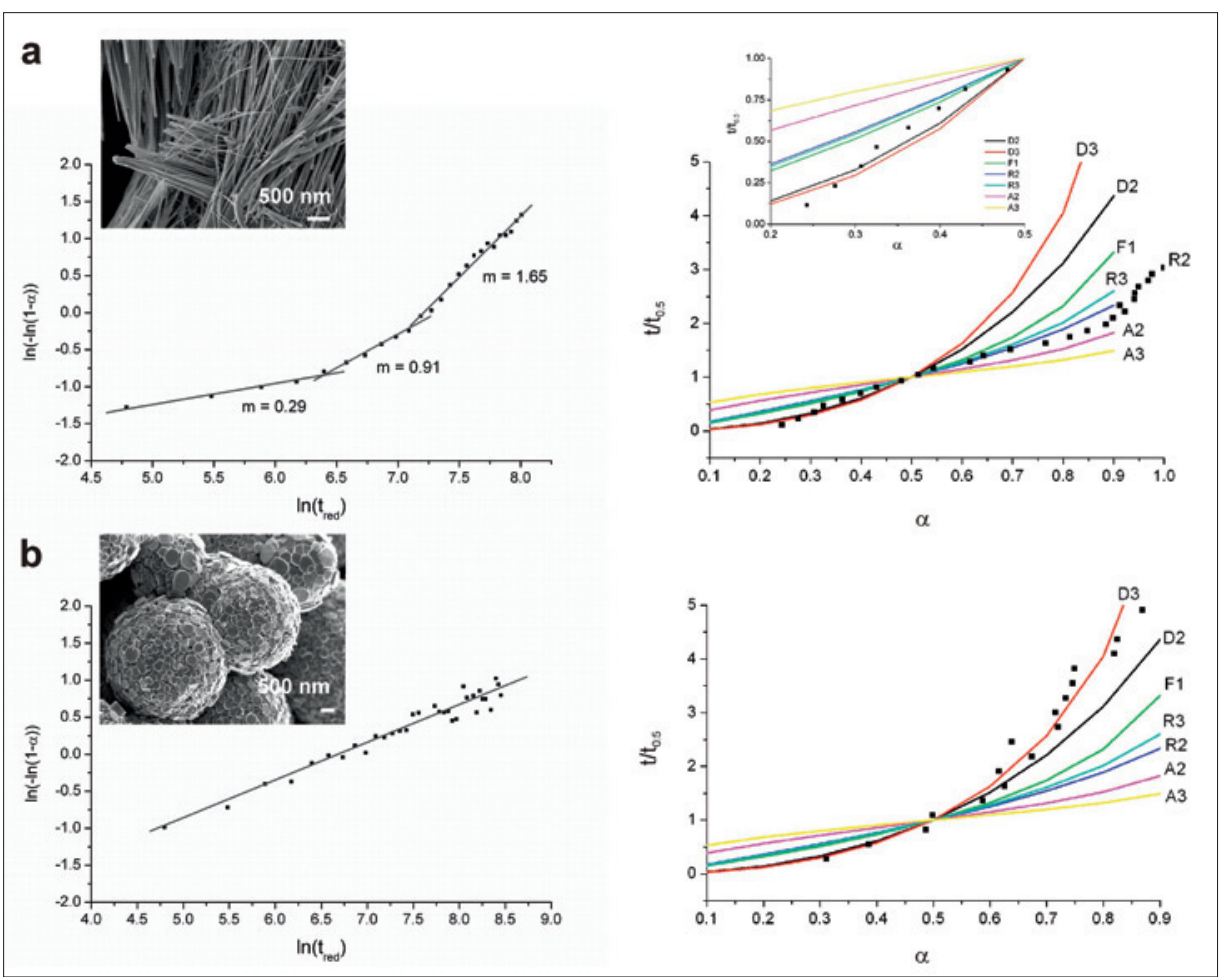

Fig. 2. Sharp-Hancock plots (left column) and comparison of the evolution of experimental $t / t_{0.5}$ data as a function of $\alpha$ (black squares) with different theoretical models (right column) of the alkali W/Mo-HTB oxide formation in the presence of (a) $\mathrm{LiCl}$ and (b) $\mathrm{CsCl}$ (insets: representative SEM images of the products).

Moreover, our most recent investigations revealed that the type of alkali cation not only influences the morphology of the W/ Mo-oxides but also their sensing properties in ammonia detection. This illustrates our three-step strategy towards oxide nanomaterials (synthesis - mechanisms - applications) and leads over to their implementation for the above-mentioned goals of materials chemistry.

\section{Environmental Application of Oxide Nanomaterials}

\subsection{Photocatalytically Active Bismuth-containing Oxides}

Ever since water splitting under UV light irradiation on a $\mathrm{TiO}_{2}$ electrode was first reported in 1972, ${ }^{[28]}$ most research efforts in the field of oxide-based photocatalysis have been directed on this target oxide. [29] Despite its low-cost and nontoxic features, however, $\mathrm{TiO}_{2}$ is limited to UV light activation, thereby leaving $96 \%$ of the incident solar light unused. As a consequence, a wide range of potential ternary oxide photocatalysts is currently being screened by many research groups and bismuth vanadate, $\mathrm{BiVO}_{4}$, has emerged as one of the most promising visible-light-driven candidates. ${ }^{[30]}$ This layered vanadate exists in three modifications: the tetragonal zircon and scheelite types and the monoclinic scheelite form. The enhanced absorption features of the monoclinic $\mathrm{BiVO}_{4}$ modification are due to its smaller band gap (2.4 $\mathrm{eV}$ ) in comparison with $\mathrm{TiO}_{2}(3.2 \mathrm{eV})$. According to DFT calculations, the valence band of $\mathrm{BiVO}_{4}$ is formed from $\mathrm{Bi} 2 \mathrm{~s}$ and $\mathrm{O}$ $2 p$ hybrid orbitals, whereas the conduction band consists of unoccupied V 3d states leading to a minimum at the Brillouin zone edge that is suitable for low energy direct transitions. ${ }^{[30,31]}$ The electronic structure of bismuth vanadate can be further tuned through doping with transition metal cations. Generally, the efficiency of a photocatalytic material depends on a manifold parameters, such as crystallinity, particle size and surface area: ideal photocatalysts should combine small particle sizes with high surface areas and a high degree of crystallinity. Although monoclinic $\mathrm{BiVO}_{4}$ has been accessed with a variety of synthetic methods ranging from solid state reactions over sonochemical processes to hydrothermal treatments, the majority of these preparative pathways led to materials with unfavorably low surface areas and large particle sizes. ${ }^{[32]}$ Recently, we have thus reported on a new additive-assisted hydrothermal pathway to photocatalytically active $\mathrm{BiVO}_{4} \cdot{ }^{[33]}$ Screening experiments revealed that the presence of $\mathrm{K}_{2} \mathrm{SO}_{4}$ as an additive directs the hydrothermal reaction of the precursor materials $\mathrm{Bi}\left(\mathrm{NO}_{3}\right)_{3} \cdot 5 \mathrm{H}_{2} \mathrm{O}$ and $\mathrm{V}_{2} \mathrm{O}_{5}$ at $200{ }^{\circ} \mathrm{C}$ towards $\mathrm{BiVO}_{4}$ crystals with average dimensions around $150 \mathrm{~nm}$ and their surface area $\left(15.6 \mathrm{~m}^{2} / \mathrm{g}\right)$ is en- 

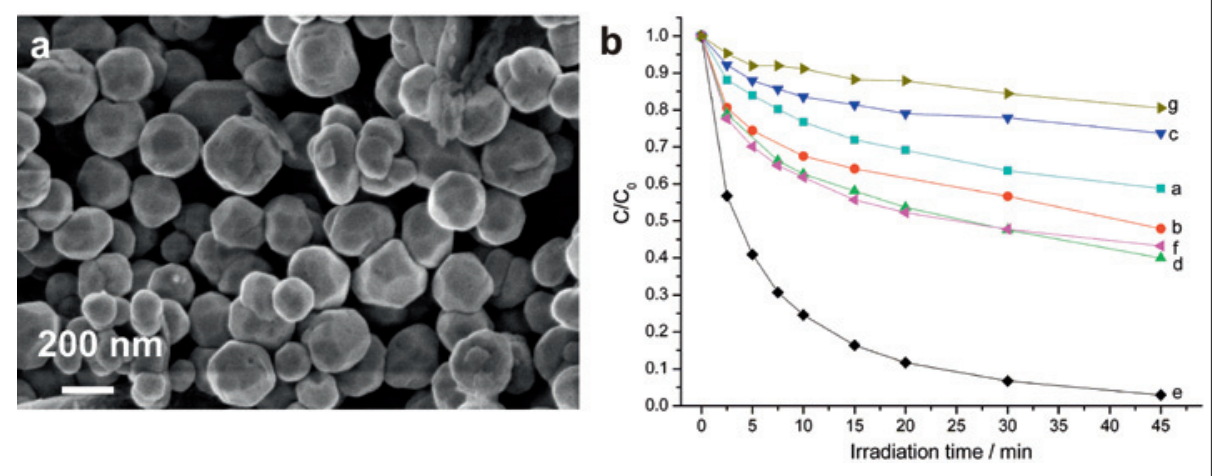

Fig. 3. (a) Representative SEM image of $\mathrm{BiVO}_{4}$ particles synthesized in the presence of $\mathrm{K}_{2} \mathrm{SO}_{4}$ as a hydrothermal additive; (b) degradation of $\mathrm{MB}$ in the presence of different photocatalysts under visible light irradiation (a-d: $\mathrm{BiVO}_{4}$ reference compounds, e: $\mathrm{BiVO}_{4}$ particles depicted in the left SEM image; g: P25 as a $\mathrm{TiO}_{2}$ standard; catalyst: 50 mg, light source: $\mathrm{Hg}$ bulbs, max. intensity at $450 \mathrm{~nm})$.
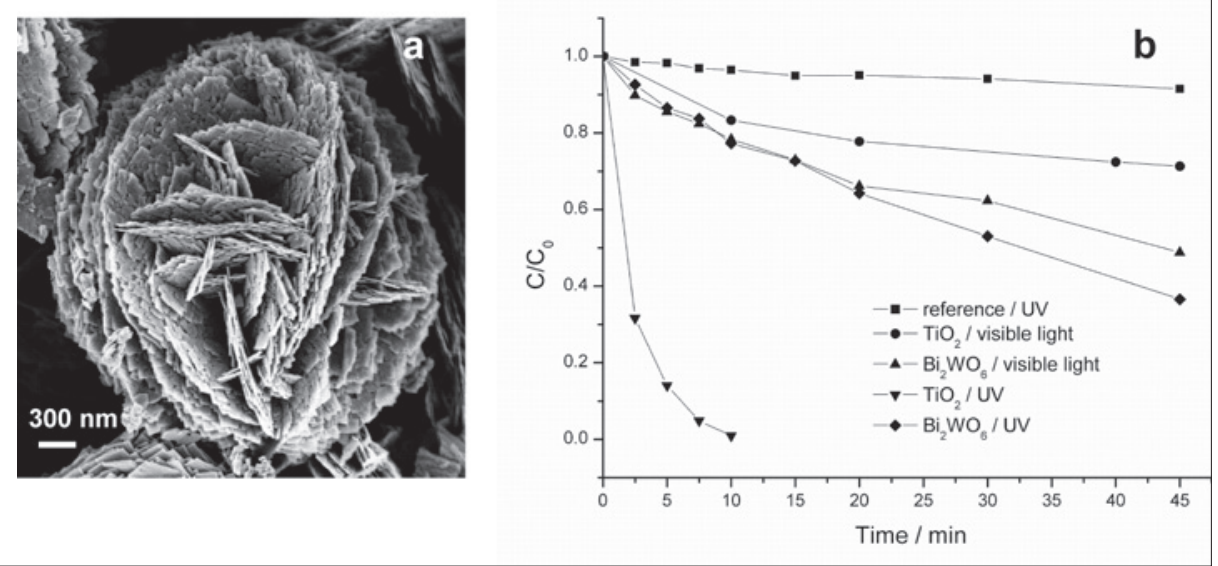

Fig. 4. (a) Representative SEM image of hierarchical $\mathrm{Bi}_{2} \mathrm{WO}_{6}$ microspheres and (b) degradation of RhB monitored at $554 \mathrm{~nm}$ as a function of the irradiation time (UV and visible light) in the presence of $\mathrm{Bi}_{2} \mathrm{WO}_{6}$ and $\mathrm{TiO}_{2}$ as a standard $(\mathrm{P}-25)$.

hanced in comparison with additive-free reactions (Fig. 3a).

The band gap of the $\mathrm{BiVO}_{4}$ particles was determined as $2.47 \mathrm{eV}$ from UV-vis spectra and their photocatalytic performance was evaluated with standard tests, namely the decomposition of methylene blue (MB) as an organic model dye for environmental pollutants. The photocatalytic activities of $\mathrm{BiVO}_{4}$ samples with different morphologies obtained from hydrothermal parameter variations are shown in Fig. $3 b$ and the $\mathrm{BiVO}_{4}$ particles grown with $\mathrm{K}_{2} \mathrm{SO}_{4}$ as an additive clearly outperform the reference compounds. This was further verified through a comparison with $\mathrm{BiVO}_{4}$ microtubes synthesized according to literature protocols, ${ }^{[34]}$ because the $\mathrm{BiVO}_{4}$ crystals displayed a three-fold higher photocatalytic activity than their tubular form. In addition to the high surface area, the crystallinity of the $\mathrm{BiVO}_{4}$ materials is another key factor for the enhanced photodecomposition of MB. Firstly, the high surface area provides more active sites for the induction of the decomposition reaction. Secondly, the small particle size minimizes the sites for the recombination of light-generated electron-hole pairs so that they can be more efficiently transferred to the surface for the degradation of absorbed MB molecules. The recombination process is also impeded through the high degree of crystallinity of the $\mathrm{BiVO}_{4}$ particles. ${ }^{[33]}$

Interestingly, $\mathrm{K}_{2} \mathrm{SO}_{4}$ plays a more active role in the hydrothermal process beyond that of a mere additive, because it leads to the formation of potassium vanadate fibers with larger overall dimensions (lengths up to several tens of micrometers with diameters around $50 \mathrm{~nm}$ ) as a side product. They can thus be separated mechanically from the main product $\mathrm{BiVO}_{4}$ particles and their structural motif is currently under investigation, because the low degree of crystallinity of the nanorods and their instability during HRTEM investigations render this a difficult problem. Generally, the structure determination of novel nanoparticles with highly anisotropic morphologies is a chal- lenging task that often requires a combination of different diffraction and electron microscopy techniques ( $c f$. Section 4.2).

The as-synthesized $\mathrm{BiVO}_{4}$ particles were furthermore investigated with respect to oxygen evolution in $\mathrm{AgNO}_{3}$ solutions. Here, $\mathrm{Ag}^{+}$acts as a thermodynamically favorable acceptor for photo-excited electrons as the redox potential of $\mathrm{Ag}^{+} / \mathrm{Ag}$ ( 0.799 vs. NHE) is higher than the conduction band potential of $\mathrm{BiVO}_{4}\left(\mathrm{E}_{\mathrm{CB}}=0.33\right.$ $\mathrm{V}$ vs. NHE). Although the $\mathrm{O}_{2}$ evolution rate of the $\mathrm{BiVO}_{4}$ crystals is promising during the first cycle $(428 \mu \mathrm{mol} / \mathrm{h} / \mathrm{g})$, it decreases over the following cycles due to a mechanical loss of catalyst during recollection. This illustrates the key practical problem of immobilizing photocatalysts in solutions whilst keeping their surface areas sufficiently large for high catalytic performances. Furthermore, other hydrothermally obtained $\mathrm{BiVO}_{4}$ particles with a lower surface area than the sample depicted in Fig. 3 a displayed comparable or even higher $\mathrm{O}_{2}$ evolution rates. This observation points to different paradigms for the development of oxide catalysts for photodegradation and water splitting processes, respectively: the key factor for the latter target reaction is the optimal combination of electronic structure and crystallinity and the surface areas are less decisive than for photocatalytic decompositions.

Among the large family of bismuthcontaining oxides, $\mathrm{Bi}_{2} \mathrm{WO}_{6}$ keeps attracting research attention due to its wide range of physico-chemical properties including ferroelectricity, ${ }^{[35]}$ nonlinear dielectric susceptibility ${ }^{[36]}$ and oxide anion conductivity. ${ }^{[37]}$ These interesting features are linked to the flexible Aurivillius-type layered structure of $\mathrm{Bi}_{2} \mathrm{WO}_{6}$ that is constructed from alternating sheets of $\left[\mathrm{WO}_{4}\right]_{\mathrm{n}}{ }^{2-}$ sheets consisting of corner-sharing $\mathrm{WO}_{6}$ octahedra and $\left[\mathrm{Bi}_{2} \mathrm{O}_{2}\right]_{\mathrm{n}}{ }^{2+}$ slabs. ${ }^{[38]}$ Moreover, $\mathrm{Bi}_{2} \mathrm{WO}_{6}$ displays promising visible-light-driven photocatalytic properties in the $\mathrm{O}_{2}$ evolution from $\mathrm{AgNO}_{3}$ solutions ${ }^{[39]}$ as well as in the degradation of organic compounds under visible light irradiation. ${ }^{[40]}$ These key materials properties can be further enhanced through the construction of $\mathrm{Bi}_{2} \mathrm{WO}_{6}$ nanoarchitectures. ${ }^{[41]}$ Therefore, we have developed a straightforward route to flower-like hierarchical assemblies of $\mathrm{Bi}_{2} \mathrm{WO}_{6}$ nanoplatelets starting from the hydrothermal reaction of $\mathrm{Bi}\left(\mathrm{NO}_{3}\right)_{3} \cdot 5 \mathrm{H}_{2} \mathrm{O}$ with $\mathrm{K}_{2} \mathrm{WO}_{4}$ at $160{ }^{\circ} \mathrm{C}$ (Fig. 4). ${ }^{[42]}$

In comparison to alternative synthetic procedures, our approach relies on an efficient self-organization process in solution as the most direct pathway to photocatalytically active $\mathrm{Bi}_{2} \mathrm{WO}_{6}$ nano-architectures to date. The obtained $\mathrm{Bi}_{2} \mathrm{WO}_{6}$ nanoflowers show high visible-light-driven photocatalytic activities in the decomposition of Rhodamine $\mathrm{B}(\mathrm{RhB})$ as a model dye 
(64\% degradation of RhB within $45 \mathrm{~min}$. of irradiation, $c f$. Fig. 4) due to their high BET surface areas $\left(17.4 \mathrm{~m}^{2} / \mathrm{g}\right)$. Parameter investigations of the hydrothermal formation process revealed the crucial influence of the $\mathrm{pH}$ value on the phase and morphology of the products and the use of $\mathrm{K}_{2} \mathrm{SO}_{4}$ as an additive opens up new pathways to metastable cubic $\gamma-\mathrm{Bi}_{2} \mathrm{O}_{3}$ or $\mathrm{Bi}_{384} \mathrm{~W}_{016} \mathrm{O}_{624}$.

As mentioned above, $\mathrm{TiO}_{2}$ is still the most popular photocatalytic material despite its limitation of light absorption to the UV range and the technical difficulties in the separation and recycling of small $\mathrm{TiO}_{2}$ catalyst particles. Both problems can in principle be addressed through the construction of heterojunctions between $\mathrm{TiO}_{2}$ and a second oxide that can also enhance the lifetime of photoinduced electronhole pairs: ${ }^{[43]}$ n-type $\mathrm{Bi}_{2} \mathrm{O}_{3} / \mathrm{TiO}_{2}$ heterojunctions, for example, display enhanced visible-light-driven photocatalytic activities due to the direct combination of two semiconductors although the resulting products were a rather random mixture of both oxides. ${ }^{[44]}$ We have thus established a facile method for the convenient solutionbased coating of hierarchical $\mathrm{Bi}_{2} \mathrm{WO}_{6}$ microspheres with anatase $\mathrm{TiO}_{2}$ nanoparticles of $10-40 \mathrm{~nm}$ in size (Fig. 5).[45]

These composites are available from a single hydrothermal coating step in the presence of $\mathrm{TiF}_{4}$ as a precursor and no additional post-treatments are required. Electron microscopy analyses showed the presence of genuine heterostructures consisting of crystalline $\mathrm{TiO}_{2}$ particles that are firmly attached to the crystal facets of the nanostructured $\mathrm{Bi}_{2} \mathrm{WO}_{6}$ substrates. Degradation experiments with methylene blue (MB) as a reference compound furthermore demonstrated the benefits of composite formation, because their photocatalytic activity is enhanced in comparison with isolated $\mathrm{Bi}_{2} \mathrm{WO}_{6}$ microspheres and $\mathrm{TiO}_{2}$ nanoparticles, respectively. ${ }^{[45]}$

\subsection{Bismuth Oxysulfate Nanowires for Humidity Sensing}

The hydrothermal treatment of $\alpha-\mathrm{Bi}_{2} \mathrm{O}_{3}$ in the presence of $\mathrm{K}_{2} \mathrm{SO}_{4}$ is an interesting example for the unexpected formation of a new nanomaterial from a process that was originally designed as an additivecontrolled transformation of the commercial bulk oxide into nanowires. ${ }^{[46]}$ After treatment of the precursors at $160{ }^{\circ} \mathrm{C}$, SEM investigations of the product indeed showed the formation of high aspect ratio nanowires with diameters in the range of 100-300 $\mathrm{nm}$ and lengths exceeding several tenths of micrometers (Fig. 6).

As can be seen from the TEM images in Fig. 6a, these nanowires are organized into bundles of smaller fibers with diameters around $50 \mathrm{~nm}$. As pointed out above ( $\mathrm{Sec}-$ tion 4.1), the structural analysis of such
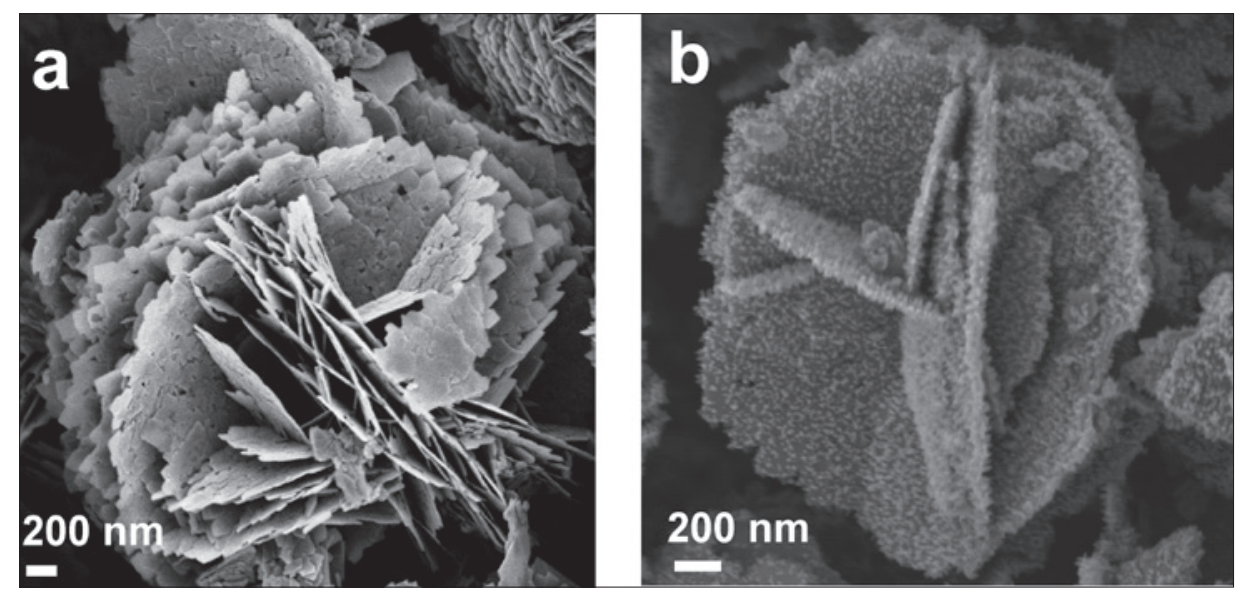

Fig. 5. Representative SEM images of nanostructured $\mathrm{Bi}_{2} \mathrm{WO}_{6}$ images before (a) and after coating with anatase $\mathrm{TiO}_{2}$ nanoparticles (b).
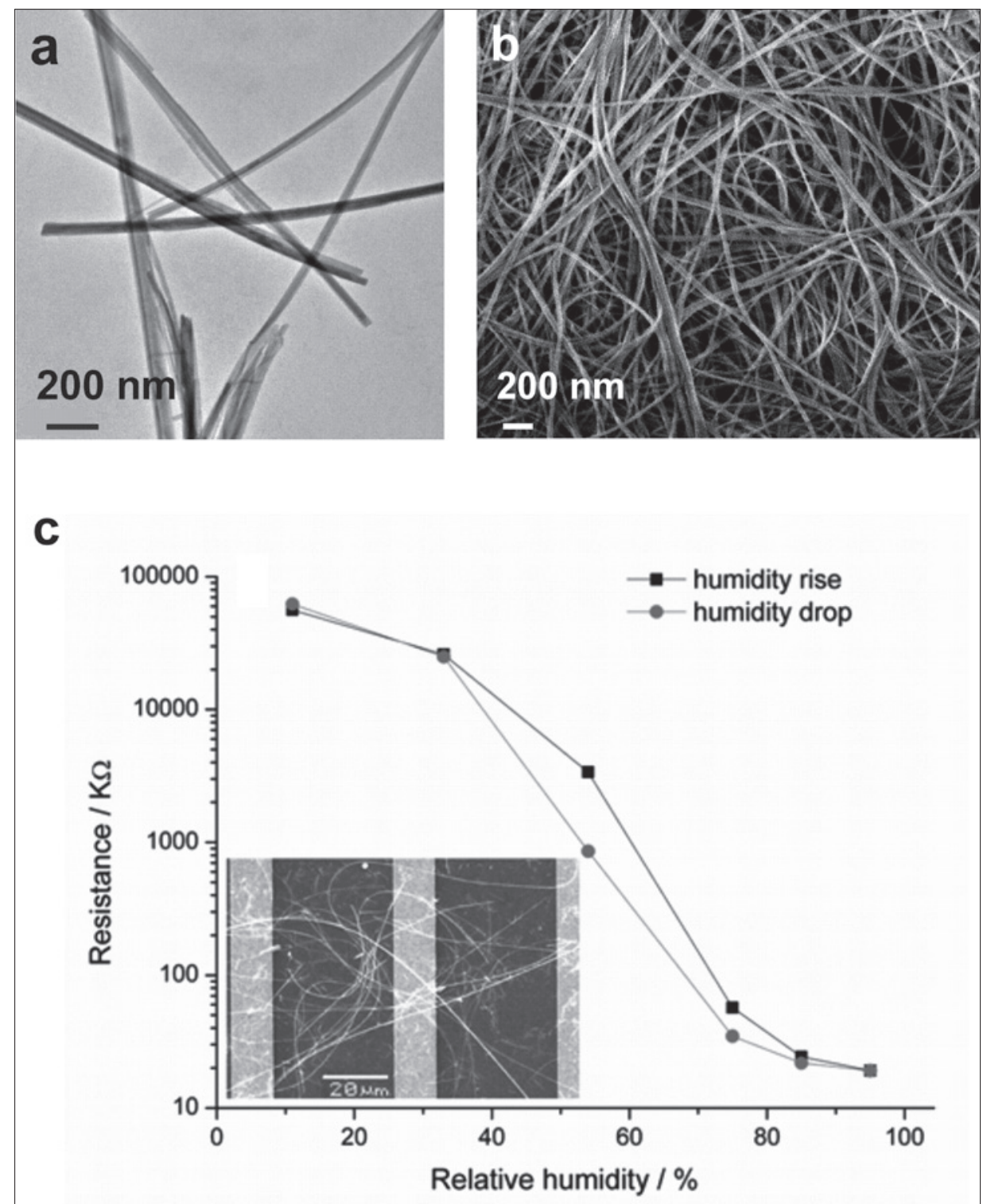

Fig. 6. (a) Representative TEM and (b) SEM images of $\mathrm{Bi}_{6} \mathrm{~S}_{2} \mathrm{O}_{15}$ nanowires and (c) humidity hysteresis of the $\mathrm{Bi}_{6} \mathrm{~S}_{2} \mathrm{O}_{15}$ nanowire sensor (inset: SEM image of the nanowire sensor chip).

highly anisotropic materials with a rather low degree of crystallinity is quite difficult, especially when neither sufficient quantities for neutron diffraction experiments nor isostructural single crystals are available. Therefore, we applied a combination of electron diffraction tilting experiments, Rietveld refinements and HRTEM inves- 
tigations to elucidate the structure of the nanowires. They represent a new type of bismuth oxysulfates, namely $\mathrm{Bi}_{6} \mathrm{~S}_{2} \mathrm{O}_{15}$, that differs from the hitherto known representatives: here, linear $\left(\mathrm{Bi}_{12} \mathrm{O}_{14}\right)_{n}^{8 \mathrm{n}+}$ columns are surrounded with sulfate tetrahedra, ${ }^{[47]}$ whilst all other bismuth oxysulfates are derivatives of the structurally entirely different fluorite-type that is based on a close packing of oxygen atoms. ${ }^{[48]}$

Furthermore, we tried to investigate the reaction pathway with in situ EDXRD methods, but this otherwise widely applicable method failed to bring forward useful information about the reaction kinetics due to two problems: the low crystallinity of the nanowires renders the onset of their formation generally difficult to detect besides the strongly scattering starting material $\alpha-\mathrm{Bi}_{2} \mathrm{O}_{3}$ and on top of that, the strongest reflections of $\mathrm{Bi}_{6} \mathrm{~S}_{2} \mathrm{O}_{15}$ and $\alpha-\mathrm{Bi}_{2} \mathrm{O}_{3}$ practically coincide despite the different crystal structures of precursor and product. Therefore, we applied state-of-the-art in situ QEXAFS (quick scanning EXAFS) measurements to track the course of the reaction both in the liquid and in the solid phase. ${ }^{[22]}$ The results revealed that $c a .0 .4$ mol\% Bi were dissolved during the reaction at $160{ }^{\circ} \mathrm{C}$ and the good time resolution of this technique permitted the exclusion of intermediates. Additional information about the reaction kinetics was obtained from a combination of ex situ quenching experiments and SEM investigations: the products obtained between $5 \mathrm{~min}$ and $2 \mathrm{~h}$ of hydrothermal treatment consist of bulk $\mathrm{Bi}_{2} \mathrm{O}_{3}$ that is overgrown with an increasingly thick film of nanowires and the conversion process takes $72 \mathrm{~h}$ to completion. All in all, we concluded that the $\mathrm{Bi}_{6} \mathrm{~S}_{2} \mathrm{O}_{15}$ nanowires are formed from a two-step sequence that is initiated by a minute dissolution of the $\mathrm{Bi}_{2} \mathrm{O}_{3}$ precursor, followed by $\mathrm{Bi}_{6} \mathrm{~S}_{2} \mathrm{O}_{15}$ nucleation and further growth of nanowires at the solid/liquid interface. The anisotropic facilities of the columnar $\mathrm{Bi}_{6} \mathrm{~S}_{2} \mathrm{O}_{15}$ structure probably facilitate the formation of long nanowires. Interestingly, the participation of the ionic additive substance $\mathrm{K}_{2} \mathrm{SO}_{4}$ leads to a modification of the anionic lattice of the products instead of the more frequently observed incorporation of the cationic additive part ( $c f$. Section 3 ). This hypothesis was confirmed through the extension of the above hydrothermal protocol upon the formation of $\mathrm{Bi}_{6} \mathrm{Cr}_{2} \mathrm{O}_{15}$ nanowires from $\mathrm{Bi}_{2} \mathrm{O}_{3}$ and $\mathrm{K}_{2} \mathrm{CrO}_{4} \cdot{ }^{\cdot[7]}$ This opens up new hydrothermal tuning routes for oxide nanomaterials through substitution reactions in the anionic sublattice. Although this interesting approach amplifies the oxide family with new oxynitrides, oxysulfate, oxyfluorides etc., it is still less explored than the commonly applied cationic substitution strategies. [49]

Moreover, we investigated the hu- midity sensing properties of the $\mathrm{Bi}_{6} \mathrm{~S}_{2} \mathrm{O}_{15}$ nanowires that were deposited onto prefabricated $\mathrm{Au}$ interdigital electrodes. ${ }^{[46]}$ Humidity sensors in general are important tools for numerous applications in industry and everyday life and their miniaturization through the use of highly sensitive nanowires is therefore an important technological task. ${ }^{[50]}$ Metal oxide semiconductors are especially suitable for humidity sensors due to their excellent water adsorption and desorption features that can be monitored through their humidity-dependent electrical characteristics. ${ }^{[51]}$ The $\mathrm{Bi}_{6} \mathrm{~S}_{2} \mathrm{O}_{15}$ nanowires are promising candidates for this purpose due to their high sensitivity: their resistance changes over three orders of magnitude (from $\mathrm{ca}$. $10^{7} \Omega$ to $10^{4} \Omega$ ) in the relative humidity range between $11 \%$ and $95 \%$. Dynamic tests also proved their fast response and recovery behavior as additional prerequisites for technical applications. As their reproducibility over several measurement cycles was also satisfying, further studies are now in progress.

In summary, this multi-disciplinary case study on $\mathrm{Bi}_{6} \mathrm{~S}_{2} \mathrm{O}_{15}$ nanowires illustrates our strategy: the synergistic interaction of structural chemistry, mechanistic investigations and application-oriented studies.

\section{Conclusions}

The structural diversity and the wide property spectrum of oxides provide an ever-increasing substance pool for the discovery and targeted development of new nanomaterials. Therefore, nanostructured oxides are essential tools for the solution of tomorrow's energy and environmental problems. Oxide nanomaterials research has become a dynamic interdisciplinary field where structural science, analytics and physical chemistry work hand in hand to characterize and tailor new materials for the growing demands of industrial technology. Our application-oriented contribution to today's materials research is focused on the facile and 'green' synthesis of nanoscale oxides for photocatalysts and sensors. Here, the long-term technological targets are robust oxide systems for water splitting and personalized nanowire-based sensors for everyday environmental control. On the methodological level, we focus on the mechanistic understanding of hydrothermal processes to facilitate their scale-up. Due to the nonlinear aspects of hydrothermal reactions, their large-scale implementation remains a risky problem that is still in the way of their widespread industrial applications. In situ methods are a powerful option to elucidate the principles behind the solution growth of anisotropic oxide materials and to single out the key process parameters. Furthermore, we pursue the tuning of hydrothermal reactions with ionic additives that open up new avenues to optimized production strategies and to the formation of new oxide nanomaterials. In summary, we apply a comprehensive strategy for materials development that is based on three interconnected pillars: structural chemistry, mechanistic studies and technical implementation.

\section{Acknowledgements}

The support of the Electron Microscopy ETH Zurich, EMEZ, and of the Center for Microscopy and Image Analysis, University of Zurich, is gratefully acknowledged. We wish to thank Prof. Dr. Jan-Dierk Grunwaldt (Karlsruhe Institute of Technology, Germany) for his generous support with in situ XAS studies and Prof. Dr. Wolfgang Bensch (University of Kiel, Germany) for the fruitful collaboration on in situ EDXRD investigations. The authors are grateful to Prof. Dr. Guorong Chen and Mr. Kaibo Zheng (Department of Materials Science, Fudan University, Shanghai) for the investigation of oxide sensing properties. Financial support from the Sino Swiss Science and Technology Cooperation (SSSTC, project no. EG05-092008) and from the NCCR MaNEP (Materials with Novel Electronic Properties) is gratefully acknowledged. We thank the Swiss National Science Foundation (SNF Professorship PP002-114711/1) and the University of Zurich for financial support.

Received: February 16, 2010

[1] M. Zach, C. Hagglund, D. Chakarov, B Kasemo, Curr. Opin. Solid State Mater. Sci. 2006, 10, 132.

[2] T. Pradeep, Anshup, Thin Solid Films 2009, 517,6441

[3] D. Gust, T. A. Moore, A. L. Moore, Acc. Chem. Res. 2009, 42, 1890.

[4] P. A. Lieberzeit, F. L. Dickert, Anal. Bioanal. Chem. 2007, 387, 237.

[5] a) R. Bogue, Sensor Rev. 2009, 29, 310; b) F. Hernandez-Ramirez, J. D. Prades, R. JimenezDiaz, T. Fischer, A. Romano-Rodriguez, S. Mathur, J. R. Morante, Phys. Chem. Chem. Phys. 2009, 11, 7105.

[6] P. Anastas, N. Eghbali, Chem. Soc. Rev. 2009 , 39,301

[7] a) C. N. R. Rao, A. Müller, A. K. Cheetham, 'The Chemistry of Nanomaterials', Wiley$\mathrm{VCH}$, Weinheim, 2004; b) J. A. Rodriguez, M. Fernandez-Garcia, 'Synthesis, Properties and Applications of Oxide Nanomaterials', Wiley InterScience, 2007

[8] K. Byrappa, T. Adschiri, Prog. Cryst. Growth Charact. Mater. 2007, 53, 117.

[9] a) K. Byrappa, M. Yoshimura, 'Handbook of Hydrothermal Technologies', William Andrew Publishing, New Jersey, 2001; b) G. R. Patzke, F. Krumeich, R. Nesper, Angew. Chem., Int. Ed. 2002, 41, 2446.

[10] a) S. U. M. Khan, M. Al-Shahry, W. B. Ingler Jr., Science 2002, 297, 2243; b) Z. Zou, J. Ye, K Sayama, H. Arakawa, Nature, 2001, 414, 625; c) J. L. Falconer, K. A. Magrini-Bair, J. Catal. 1998, 179, 171.

[11] a) A. Müller, F. Peters, M. T. Pope, D. Gatteschi, Chem. Rev. 1998, 98, 239; b) U. Kortz, A Müller, J. van Slageren, J. Schnack, N. S. Dalal, 
M. Dressel, Coord. Chem. Rev. 2009, 253, 2315.

[12] F. Hussain, F. Conrad, G. R. Patzke, Angew. Chem., Int. Ed. 2009, 48, 9088; b) F. Hussain, B. Spingler, F. Conrad, M. Speldrich, P. Kögerler, C. Boskovic, G. R. Patzke, Dalton Trans. 2009, 4423.

[13] J. T. Rhule, C. L. Hill, D. A. Judd, Chem. Rev. 1998, 98, 327.

[14] G. A. Ozin, L. Cademartiri, Small 2009, 5, 1240.

[15] a) T. H. Ha, H. J. Koo, B. H. Chung, J. Phys. Chem. C 2007, 111, 1123; b) M. H. Kim, B. Lim, E. P. Lee, Y. Xia, J. Mater. Chem. 2008, 18, 4069; c) M. J. Siegfried, K. S. Choi, J. Am. Chem. Soc. 2006, 128, 10356.

[16] A. Michailovski, R. Kiebach, W. Bensch, J. D. Grunwaldt, A. Baiker, S. Komarneni, G. R. Patzke, Chem. Mater. 2007, 19, 185.

[17] C. N. R. Rao, B. Raveau, 'Transition Metal Oxides', 2nd Ed., Wiley-VCH, Weinheim, 1998.

[18] a) R. N. Vannier, G. Mairesse, F. Abraham, G. Nowogrocki, J. Solid State Chem. 1996, 122, 394; b) J. Yu, A. Kudo, Chem. Lett. 2005, 34, 1528; c) A. M. Beale, M. T. Le, S. Hoste, G. Sankar, Solid State Sci. 2005, 7, 1141.

[19] J.-D. Guo, K. P. Reis, M. S. Whittingham, Solid State Ionics 1992, 53-56, 305.

[20] A. Michailovski, F. Krumeich, G. R. Patzke, Chem. Mater. 2004, 16, 1433.

[21] R. Kiebach, N. Pienack, W. Bensch, J.-D. Grunwaldt, A. Michailovski, A. Baiker, T. Fox, Y. Zhou, G. R. Patzke, Chem. Mater. 2008, 20, 3022.

[22] a) J.-D. Grunwaldt, M. Ramin, M. Rohr, A. Michailovski, G. R. Patzke, A. Baiker, Rev Sci. Instr. 2005, 76, 054104; b) J. Stötzel, D. Luetzenkirchen-Hecht, E. Fonda, N. De Oliveira, V. Briois, R. Frahm, Rev. Sci. Instr 2008, 79, 083107; c) D. Luetzenkirchen-Hecht, J.-D. Grunwaldt, M. Richwin, B. Griesebock, A. Baiker, R. Frahm, Physica Scr. 2005, T115, 831 ; d) J.-D. Grunwaldt, M. Beier, B. Kimmerle, A. Baiker, M. Nachtegaal, B. Griesebock, D. Luetzenkirchen-Hecht, J. Stötzel, R. Frahm, Phys. Chem. Chem. Phys. 2009, 11, 8779.

[23] A. Michailovski, J.-D. Grunwaldt, A. Baiker, R. Kiebach, W. Bensch, G. R. Patzke, Angew. Chem., Int. Ed. 2005, 44, 5643.
[24] a) R. Kiebach, N. Pienack, M. E. Ordolff, F. Studt, W. Bensch, Chem. Mater. 2006, 18, 1196; b) R. I. Walton, D. O'Hare, Chem. Commun. 2000, 23, 2283; c) A. M. Beale, L. M. Reilly, G. Sankar, Appl. Catal. A 2007, 325, 290.

[25] a) J. D. Hancock, J. H. Sharp, J. Am. Ceram. Soc. 1972, 55, 74; b) J. H. Sharp, G. W. Brindley, B. N. Narahari Achar, J. Am. Ceram. Soc. 1966, 379; c) B. M. Mohamed, J. H. Sharp, J. Mat. Sci. 1997, 1595.

[26] a) M. Avrami, J. Chem. Phys. 1939, 7, 1103; b) M. Avrami, J. Chem. Phys. 1940, 8, 212; (c) M. Avrami, J. Chem. Phys. 1941, 9, 177.

[27] Y. Zhou, N. Pienack, W. Bensch, G. R. Patzke, Small 2009, 17, 1978.

[28] A. Fujishima, K. Honda, Nature 1972, 238, 37.

[29] a) M. R. Hoffmann, S. T. Martin, W. Choi, D. W. Bahneman, Chem. Rev. 1995, 95 69; b) M. Yan, F. Chen, J. Zhang, M. Anpo, J. Phys. Chem. B 2005, 109, 8673 .

[30] A. Kudo, K. Omori, H. Kato, J. Am. Chem. Soc. 1999, 121, 11459.

[31] a) A. Walsh, Y. F. Yan, M. N. Huda, M. M. AlJassim, S. H. Wei, Chem. Mater. 2009, 21, 547; b) J. Tang, Z. Zou, J. Ye, Angew. Chem., Int. Ed. 2004, 43, 4463; c) A. Hameed, T. Montini, V. Gombac, P. Fornasiero, J. Am. Chem. Soc. 2008, 130, 9658.

[32] a) H. Q. Jiang, H. Endo, H. Natori, M. Nagai, K. Kobayashi, J. Eur. Ceram. Soc. 2008, 28, 2955; b) L. Zhou, W. Z. Wang, S. W. Liu, L. S. Zhang, H. L. Xu, W. Zhu, J. Mol. Catal. A: Chem. 2006, 252, 120.

[33] Y. Zhou, K. Vuille, A. Heel, B. Probst, R. Kontic, G. R. Patzke, Appl. Catal. A 2010, 375, 140.

[34] L. Zhou, W. Z. Wang, L. S. Zhang, H. L. Xu, W. Zhu, J. Phys. Chem. C 2007, 111, 13659.

[35] N. A. McDowell, K. S. Knight, P. Lightfoot, Chem. Eur. J. 2006, 12, 1493.

[36] M. Hamada, H. Tabata, T. Kawai, Thin Solid Films 1997, 306, 6.

[37] Z. G. Yi, Y. X. Li, Z. Y. Wen, S. R. Wang, J. T. Zeng, Q. R. Yin, Appl. Phys. Lett. 2005, 86, 192906.

[38] J. Ricote, L. Pardo, A. Castro, P. Millan, J. Solid State Chem. 2001, 160, 54.

[39] A. Kudo, S. Hijii, Chem. Lett. 1999, 10, 1103.

[40] J. W. Tang, Z. G. Zou, J. H. Ye, Catal. Lett. 2004, 92, 53 .
[41] a) Y. Y. Li, J. P. Liu, X. T. Huang, G. Y. Li, Cryst. Growth Des. 2007, 7, 1350; b) J. Wu, F. Duan, Y. Zheng, Y. Xie, J. Phys. Chem. C 2007, 111, 12866; c) L. S. Zhang, W. Z. Wang, L. Zhou, H. L. Xu, Small 2007, 3, 1618; d) S. W. Liu, J. G. Yu, J. Solid State Chem. 2008, 181, 1048.

[42] Y. Zhou, K. Vuille, A. Heel, G. R. Patzke, Z. Anorg. Allg. Chem. 2009, 635, 1848.

[43] Z. Bian, J. Zhu, S. Wang, Y. Cao, X. Qian, H. Li, J. Phys. Chem. C 2008, 112, 6258.

[44] Y. Bessekhouad, D. Robert, J. V. Weber, Catal. Today 2005, 101, 315.

[45] Y. Zhou, F. Krumeich, A. Heel. G. R. Patzke, Dalton Trans. 2010, DOI:10.1039/b926790e.

[46] Y. Zhou, J-D. Grunwaldt, F, Krumeich, K Zheng, G. Chen, J. Stötzel, R. Frahm, G. R. Patzke, Small, 2010, in print.

[47] J. Grins, S. Esmaeilzadeh, S. Hull, J. Solid State Chem. 2002, 163, 144.

[48] a) M. G. Francesconi, A. L. Kirbyshire, C. Greaves, Chem. Mater. 1998, 10, 626; b) T. E. Crumpton, C. Greaves, J. Mater. Chem. 2004, 14, 2433; c) V. I. Smirnov, V. G. Ponomareva, Yu. M. Yukhin, N. F. Uvarov, Solid State Ionics 2003, 156, 97.

[49] S. G. Ebbinghaus, H.-P. Abicht, R. Dronskowski, T. Müller, A. Reller, A. Weidenkaff, Prog. Solid. State Chem. 2009, 37, 173.

[50] a) K. Xiao, R. Li, J. Tao, E. A. Payzant, L. N. Ivanov, A. A. Puretzky, W. Hu, D. B. Geohegan, Adv. Funct. Mater. 2009, 19, 3776; b) J. Xu, W. Zhang, Z. Yang, S. Ding, C. Zeng, L. Chen, Q, Wang, S. Yang, Adv. Funct. Mater. 2009, 19, 1759 .

[51] a) X. Hu, J. Gong, L. Zhang, J. C. Yu, $A d v$. Mater. 2008, 20, 4845; b) Y. Qiu, S. Yang, $A d v$. Funct. Mater. 2007, 17, 1345. 